\title{
Strategic alliance for core competencies improvement in textile industries*
}

\author{
F. Dadashian ${ }^{1 \dagger}$, S. Shakibfar ${ }^{1}$, M. H. Fazel Zarandi ${ }^{2}$ \\ 1 Textile Engineering Department, Amirkabir University of Technology, Tehran, Iran \\ 2 Industrial Engineering Department Amirkabir University of Technology, Tehran, Iran.
}

(Received March 16 2007, Accepted April 22 2007)

\begin{abstract}
Strategic alliances are increasingly gaining popular for Textile companies to achieve fast and economical growth in today's globalization. Strategic alliances are an important source of resources, learning, and thereby core competencies improvement. So managers have to make conscious decisions to develop certain competencies so as to have all competencies that are required to be successful, firms look for strategic alliances and to leverage their partner firms' competencies. However coordination with alliance partners is not easy; each part has its own reporting process and measures, and each brings its own perspective of what it wants to contribute to the alliance and what it intents to obtain from the alliance. Transcending these informational and motivational asymmetries, as economists would phrase it, requires an open, transparent process in which both sides clearly articulate their expected contributions and their desired outcomes resulting in a document that summarizes the theory of the strategic for the alliance. Developing an Alliance Balanced Scorecard (ABS) can mitigate the natural conflict between alliance partners. It includes four-perspective framework: financial, strategic, operational, and relationship.

This study has been made on how to apply the Balanced Scorecard on an alliance-making of 8 Textile companies as a result of a demand. We aim to provide a picture of what a prospective Textile Industries could look like, for the alliance-making in Iran, by developing an Alliance Strategy Map focused on the core competencies improvement. The work has been conducted as a qualitative case study at the Textile firms in Isfahan. The scorecard was developed by using analytic hierarchy process (AHP). We argue that results based on AHP analysis would help a company to make more informed strategic management decision concerning further investment for competences and key assets development, and outsourcing non-core assets and competences. This paper reports on the results of that empirical survey, and the results show that: Maintain market position; Expanding their competencies; Gain access to complementary resources; Compete against common competitor; Reducing risk and uncertainty are important influences on alliance making for textile companies. Careful strategic planning and good partnership preparation are essential for alliance success.
\end{abstract}

Keywords: strategic alliances, textile, globalization, core competencies

\section{Introduction}

Increasing, companies are using alliance to fill gaps in their own capabilities and to grow in new markets and regions. In fact of challenge of global competition, textile companies are increasingly using strategic partnership to maintain competitiveness. Strategic alliances are "the relatively enduring inter firm co-operative arrangements, involving flows and linkages that utilize resources and, or governance structures from autonomous organizations, for the joint accomplishment of individual goals linked to the corporate mission of each sponsoring firm",[3].

Inter firm collaborations, such as strategic alliances and joint ventures, have become important business management instruments to improve the core competencies and competitiveness of companies, especially in

\footnotetext{
* thanks for funds support.

†E-mail address: dadashia@aut.ac.ir, saeed12@aut.ac.ir, zarandi@aut.ac.ir.
} 
complex and turbulent environments like textile market. Effective alliances can be growth and profitability engines in both domestic and global markets ${ }^{[7]}$. Although there seems to be an increase in the number of alliances formed, at the same time, there is also evidence that strategic alliances are underperforming. Success rates of less than 50 percent have often been cited in the literature ${ }^{[9]}$. Yet, managers are finding Partner selection is a crucial decision in many organizations, due to varying levels of risk, resource requirements, and interaction among the proposed partners. In order to succeed in such an unforgiving environment, managers need integrated decision making process that are capable of using a wide variety of models along with data and information resources available to them at various internal and external repositories ${ }^{[14]}$.

Developing an alliance Balanced Scorecard can mitigate the natural conflict between alliance partners. The Balanced Scorecard (BSC) is a model for performance competencies measures in a company with measures from different perspectives to give a more holistic view of the company's performance. The measures from the different perspectives are to give a more balanced view of the organization that reflects the different drivers that in the end contribute to an improved core competencies performance. Core competencies improvement, in order to use this in an Alliance, individuals needs to get their work done and we need to know the result of their efforts. All Textile companies, regardless of their size, keep some kind of record of their performance.Performance alliance management should be seen as a process that delivers sustainable success to organizations by improving the performance of the core competences in them and by developing the capabilities of both individuals. By seeing performance management like this, in the alliance all the work that is carried out contributes to achieving the overall purpose of the organization. By investing time and resources in performance alliance management this can lead to a competitive business advantage by improving the performance and accessibility of the business core competencies ${ }^{[1]}$. A central part of managing performance is to measure the performance. It is important to develop cause-and-effect diagrams between different strategic objectives using different perspectives. A possible approach is to use a model developed by Robert Kaplan and David Norton (1996) called the Balanced Scorecard (BSC). This model will be explained and used in this study ${ }^{[11]}$.

There is a wide range of attributed motivators for entering into and maintaining strategic alliances. Through this survey of textile firms, we have examined various characteristics of the partnerships. A threepage interview instrument was developed based on key issues identified in successful strategic alliances of textile companies. All motivation and issues of making alliances classified in four-perspective framework: financial, strategic, operational, and relationship.This study has been made on how to apply the Balanced Scorecard on an alliance-making of 8 Textile companies as a result of a demand. We aim to provide a picture of what a prospective Textile Industries could look like, for the alliance-making in Iran, by developing an Alliance Strategy Map focused on the core competencies improvement. The work has been conducted as a qualitative case study at the Textile firms in Isfahan.

Firm competencies are valuable capabilities in terms of "enabling the firm to deliver some fundamental consumer benefits" ${ }^{\text {[6] }}$. Since most of the competence characteristics are qualitative, we would resort to some subjective assessment procedure to conduct the evaluation process. Also, the necessity of conducting a multidimensional performance analysis implies solving a multi-criteria decision-making problem. Therefore we propose to use analytic hierarchy process (AHP) here due to its suitability for undertaking quantitative as well as qualitative analysis ${ }^{[6]}$. The AHP is a powerful and flexible multi-criteria decision making tool for complex problems where both qualitative and quantitative aspects need to be considered. The AHP helps the analysts to organize the critical aspects of a problem into a hierarchical structure similar to a family tree ${ }^{[13]}$.

This paper presents a structured framework for identifying the competences of firms based on "uniqueness and collectiveness characteristics". Analytic hierarchy process (AHP)-based method is developed for, respectively, evaluating competences and assets of firms. The effectiveness of our approach is demonstrated using 8 Textile manufacturing company in Iran as an example.

\subsection{Isfahan textile industries in brief}

Before World War II there were only 12 Textile mills In Isfahan province producing woven cotton and wool textiles. After that the Textile Industries expanded more until 1970 decade that their production of textiles was mainly for a protected local market. Now the problem is that the equipment in some of these mills is 
antiquated over 50 years, shuttle less looms, narrow width resulting in poor productivity, low quality and high cost. Imported fabric was also another major problem that the local mills suffered from that. Although successive governments attempted to attract investments in this sector, they failed due to the high cost of machinery, non-availability of local raw material (neither cotton nor synthetic) and the cost of labors. However, recently there has been some success with some Textile companies interesting to focus on customer's services as well as investments from some of the garment and carpet exporters. As a result, the recent globalization of the textile trade has opened up highly demanding and evolving requirements for outsourcing in textiles. The global market can play a major role in the success of the domestic textile; however low-cost imports have presented a major threat to the industrial's stability.

\subsection{The structure of strategic alliances}

The structure of Strategic alliances may be either vertical or horizontal. Vertical chain partnerships occur between partners involved in different stages in value chain (e.g., between a fiber manufacturer and a textile manufacturer), while horizontal chain partnerships occur between partners at the same stage in the value chain (e.g., between two textile manufacturers). Fig. 1 shows the strategic alliance between two competitors as the horizontal complementary strategic alliances. It can be formed to conduct business activity, such as product development, promotion or distribution. As result of turbulent competition and sweeping changes in textile technology industries, many firms desire to develop HSA whether they are manufacturers or service providers. We can expect development in quality of domestic production and exporting in future with horizontal strategic alliances between companies in one industry. But the coordination problems and risks inherent in alliances are magnified in horizontal alliances so one cannot assume that high levels of commitment or performance will occur naturally ${ }^{[2]}$.

Successful alliances are typically coalitions linking distinctive capabilities from each partner to increased their collective business value. A strategic alliance works when a wholly-owned subsidiary or acquisition is not feasible, when an evolutionary approach is desired, or when each partner recognizes its need to access critical capabilities that it is unable to develop by itself ${ }^{[8]}$.

In economic language, "at the fundamental level, relational rents are possible when alliance partners combine, exchange, or invest in idiosyncratic assets, knowledge, and resources or capabilities, and they employ effective governance mechanisms that lower transaction costs or permit the realization of rents through the synergistic combination of assets, knowledge, or capabilities" "[4].

Horizontal complementary strategic alliances are often used to increase for core competencies improvement of the partners involved. Although horizontal chain alliances usually focus on long term product and service technology development, many competitors also form joint marketing agreements. Some of these agreements not only reduce costs but also increase revenues and market power. Strategic alliance performance is significantly influenced by practice around the following critical areas: Mission, Strategy, Reciprocity, Power, Governance, Culture, Organization, Management, and Complexity.

However, horizontal alliances, formed among competitors, may have less of basis for trust. It is not likely that Horizontal alliances, therefore, will prove long lasting. This seems to be clear in the Textile alliance systems. The textile partners that manufacture same goods such as garments appear to be quite tenuous and opportunistic. Such alliances, although they do provide scale advantages, do not appear to be fertile ground for trust and long-standing partnerships. Also coordination with alliance partners is not easy; each part has its own reporting process and measures, and each brings its own perspective of what it wants to contribute to the alliance and what it intents to obtain from the alliance. Transcending these informational and motivational asymmetries, as economists would phrase it, requires an open, transparent process in which both sides clearly articulate their expected contributions and their desired outcomes resulting in a document that summarizes the theory of the strategic for the alliance.

\section{Strategic alliance motivations}

We found that uncertainty is a rationale for increase cooperation among Textile market firms. Because the technology is still uncertain as to how to combine technologies and because the expertise for each tech- 


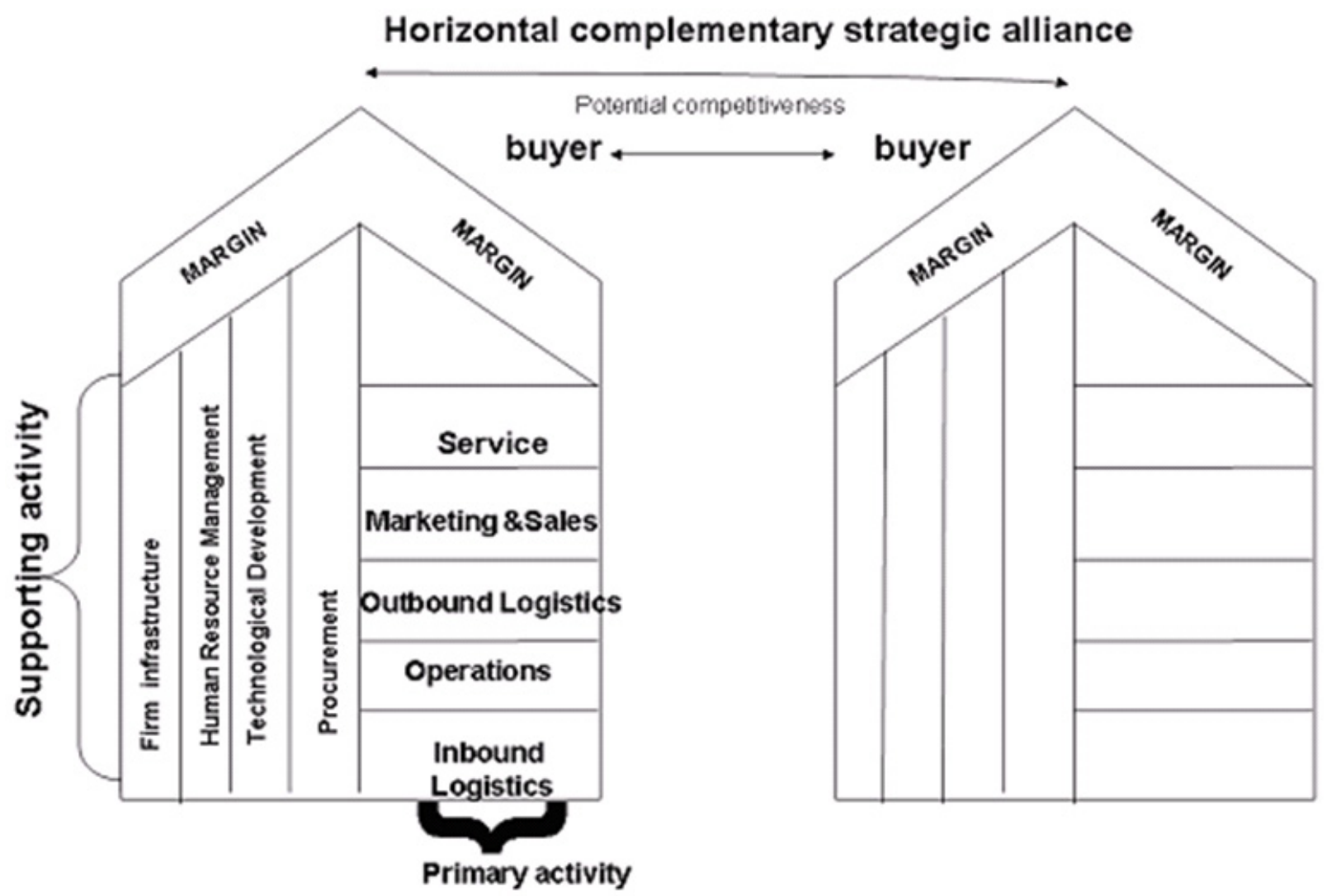

Fig. 1. Horizontal complementary strategic alliances ${ }^{[10]}$

nology is held by different companies, strategic alliances are the preferred approach until a standard emerges. Uncertainty in Textile industries can come from a number of sources: regulatory' technological, and demand. Regardless of the source of uncertainty, it leads to firms working together to manage the uncertainty in collaborative way through strategic alliances. These systems of alliances, however, are often short lived once the uncertainty disappears.

Reducing of competition also can be accomplished through industry trade organizations or government policy that is designed to reduce excessive competition, as under the Multi Fibre agreement, for example, developed countries, notably the United States, Canada and the European Union negotiated bilateral agreements with individual exporting countries to restrict exports with a view to protect their domestic industry. The quota restrictions, while limiting the volume of exports by some of the developing countries, also provided an opportunity for smaller manufacturing countries to enter the more developed apparel markets in the world. In fact, it provided a guaranteed market access to the uncompetitive manufacturer or countries resulting in many developing countries encouraging the establishment of clothing industries leading to excess production globally. Following the establishment of the WTO and the new agreement on textiles and clothing, quota restrictions will be phased out over a ten-year period from January 1995 to December 2004 resulting in a free trade in textiles and clothing from January 2005. An exception was China where some quota restrictions might continue for a further period ${ }^{[5]}$.

Also multinational corporations have achieved higher performance than firms operating domestically. As domestic economics have grown more global, the importance of international cooperative strategies has increase. Often, firms that develop distinct resources and capabilities in their home markets may be able to leverage them by making direct investment in international markets as opposed to licensing or exporting their products. International strategic alliances are a common model for making such investments in international markets. Firms can create more corporate flexibility and extend or leverage their core competencies in new geographic regions by developing international strategic alliances. However, such alliances are more complex and risky than domestic ones. For example, there is higher failure rate for international joint ventures, because they are difficult to manage. They need to coordinate and cooperate to share skills and knowledge requires 
significant processing of information on the part of all partner managers. Where significant demands are placed on partners' managers to achieve quick returns, there is less alliance success. Thus, while international cooperative strategies can have significant positive outcomes, care must be taken when choosing the particular partners, managers, and ventures to ensure success ${ }^{[10]}$.

Even as companies attempt to cooperate, they also compete, both with firms in and outside their alliances. As there are significant risks with a cooperative strategy, including such actions or outcomes as poor contract development, misrepresentation of partner firms, competencies, failure of partners to make complementary resources available, being held hostage through specific investments associated with the alliance or the partner, and misunderstanding of a partner's strategic intent (Fig. 2). Most contemporary alliances, however, are made of portfolios of firms in supply chain and shared-service units. For a company to add value, it must align its operating and service units to other to create synergy.

\section{Competitive risk}

Risk and asset management approaches

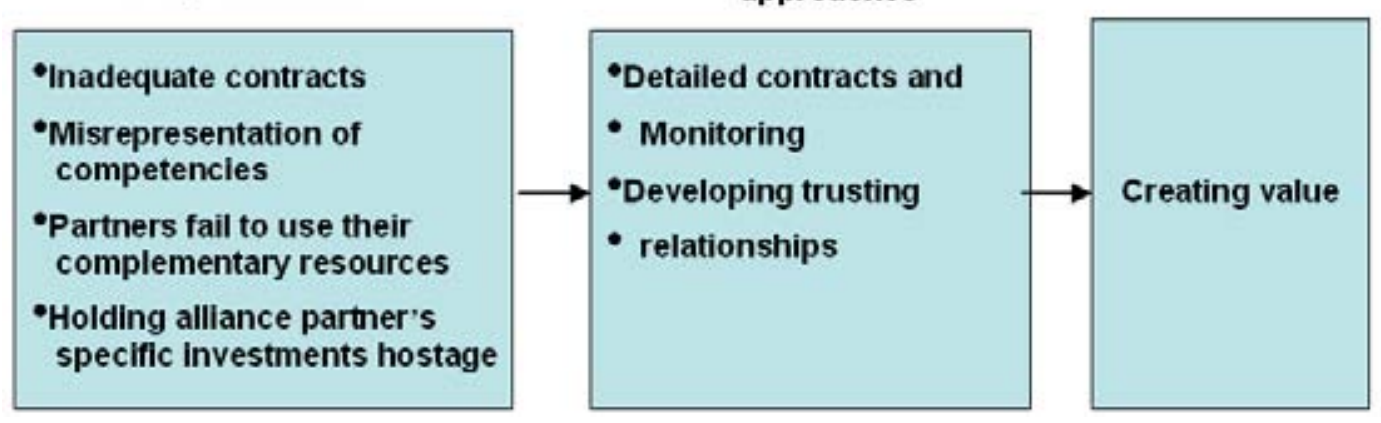

Fig. 2. Managing competitive risk in cooperative strategies ${ }^{[10]}$

It is important to develop a view of the partners and their characteristics from as many angles as possible. This is in order to get multi dimensional perspectives on the partners' and industry. For this purpose there are many models that are helpful, this study, however only deal with Porter's five competitive forces, the Internal Factors Evaluation Matrix, and SWOT (strengths/weaknesses, opportunities/threats). With the aid of a SWOT model a company can analyze what it can do (the organization's strengths and weaknesses) and what it might do in relation to alliance (external opportunities and threats). Strengths and weaknesses have to be balanced against opportunities and threats.

Identify critical factors for success, takes the descriptions and strategies outlined above to discuss and judge what is required for the vision to succeed. It will identify which factors that will have the greatest effect on the outcome. In other words, the alliance must in this step decide what are the most critical factors for success (objectives) and rank them in order of priority. We find that there are some success factors for strategic Alliance Formation and maintenance in textile companies:

1 - Maintain market position; 2 - Expanding their competencies; 3 - Gain access to complementary resources; 4 - Compete against common competitor; 5 - Reducing risk and uncertainty; 6 - Exchange of complementary technology; 7 - Faster payback on investment; 8 - Reduce competitions; 9 - Produce at lower cost location; 10 - Conform to government policy. This list of factors will then provide a base for developing key measures.

\section{Alliance balanced scorecard model}

Sharing critical resources and capabilities can also harm the development and maintenance of a firm's core competence. A firm needs to ensure that critical functions are not outsourced in order to maintain its core competences. Moreover, partnerships with firms completing work that is outsourced may not be necessary when the purchase is nonstrategic. Because partnerships can be expensive, it may be better to manage the relationship using a free market approach. Therefore, a balanced approach is required. A firm does not want 
to outsource a strategic competence nor enter into a costly partnership, so selectively choosing partners where they are critical to complement capabilities in order to improve core competencies of firm is important.The process of building an Alliance Balanced Scorecard ought to start with the most fundamental identifications for partners, such as: defining the industry, describing its development and role. The purpose is to develop a foundation for establishing an agreement on the characteristics and requirements of the industry, but also to arrive at a clear definition of the partners' current position and role. The Alliance Balanced Scorecard model should be viewed as a tool for translating an abstract vision of partnerships and strategic alliance motivations into specific measures and goals. The purpose of this step is to achieve an overall balance by translating the vision into tangible terms from the established perspectives. This process is a very important part of the actual work of core competencies development. Another important part is to formulate the overall strategy into more general terms. Developing an alliance Balanced Scorecard can mitigate the natural conflict between alliance partners. It includes four-perspective framework: financial' strategic, operational, and relationship. The process of building the strategic alliance and scorecard brings together senior decision makers from both partners to articulate clearly the objectives of alliance and the strategy for achieving those objectives demonstrated in Tab. $1^{[12]}$.

Using the scorecard in this way produces two important benefits. First, for new company provides a mechanism by which managers from the two previously independent entities have an opportunity to work together toward a common objective. The second benefit is that a language that executives can use to describe how to capture the intended synergies from alliance. Although there seems to be an increase in the number of alliances formed, at the same time, there is also evidence that strategic alliances are underperforming. Success rates of less than 50 percent have often been cited in the literature. Yet, managers are finding that Partner selection is a crucial decision in many organizations, due to varying levels of risk, resource requirements, and interaction among the proposed partners. The principal reason for poor alliance performance was an excessive concentration on achieving cost saving and insufficient attention to growing revenues. The few merged companies that succeeded focused on leveraging existing customer relationships for increased revenue, especially by retaining key revenue-generating employees. These findings provide the rationale for a firm in alliance to develop a Strategy Map and Balanced Scorecard as part of the merger integration process. Managers from the two independent companies formulate a specific strategy for leveraging the strengths of each company to create new revenue opportunities beyond what either company could have achieved operating interdentally. The process also produces a road map for implementing the revenue growth, as well as cost reduction; strategic themes through investment in key processes, employees, and information technology; and unified corporate culture.

Table 1. Alliance Balanced Scorecard model

\begin{tabular}{|c|c|}
\hline Perspective & Objectives \\
\hline Financial & $\begin{array}{l}\text { - Increase alliance revenues } \\
\text { - Reduce redundant cost across alliance members } \\
\text { - Increase partners' revenues through new customer relationships and related product sales } \\
\text { - Develop growth options for partners from alliance developing new products and new } \\
\text { customer relationships }\end{array}$ \\
\hline Strategic & $\begin{array}{l}\text { - Develop new technology } \\
\text { - Increase penetration with targeted customers } \\
\text { - Increase learning opportunities for partners' employees assigned to alliance }\end{array}$ \\
\hline Operational & $\begin{array}{l}\text { - Meet project milestone } \\
\text { - Reduce costs in manufacturing, sales, or distribution } \\
\text { - Improve product development and launch processes } \\
\text { - Enhance coordination between alliance and parents }\end{array}$ \\
\hline Relationship & $\begin{array}{l}\text { - Promote fast, effective decision making } \\
\text { - Communicate effectively within alliance and between alliance partners } \\
\text { - Build and maintain trust } \\
\text { - Develop clear roles, responsibilities, objectives, and accountabilities for alliance } \\
\text { managers and employees }\end{array}$ \\
\hline
\end{tabular}




\section{Strategy map}

Since one of the intended achievements with a Balanced Scorecard is to get the involved partners' attention, it should focus on the entity's strategy for maximum impact. The strategic alliance should inform how the company expects to create future, sustainable value. However, no two companies think about strategy in the same way. This was particularly apparent in a study made by us. Textile firms viewed strategy from a financial perspective; sales and marketing executives took a customer perspective; operations people looked at quality, cycle time, and other process perspectives; human resources professionals focused on investments in people; and get new technology. No general way to describe strategy seemed to exist. Without a shared understanding of the strategy, companies cannot create alignment around alliance. One way of creating a shared understanding of the strategy is to use a strategy map. This is based on the four-perspective model in the BSC, which provides a language where the executives can describe their firms' value-creating strategy in alliance.

The BSC strategy map (Fig. 3) provides a framework to illustrate how strategy links intangible assets to improve core competencies and value-creating processes. The customer focus describes the value proposition, which provides context for the intangible assets to create value, for targeted customers. If for instance customers value consistent quality and timely delivery, then the skills, systems, and processes that are involved in this, should be highly valuable to the organizations. If the customer values innovation and high performance, then the partners need to take high value on processes that are involved in that. Hence, consistent alignment of actions and capabilities with the customer value proposition is essential of strategy execution.

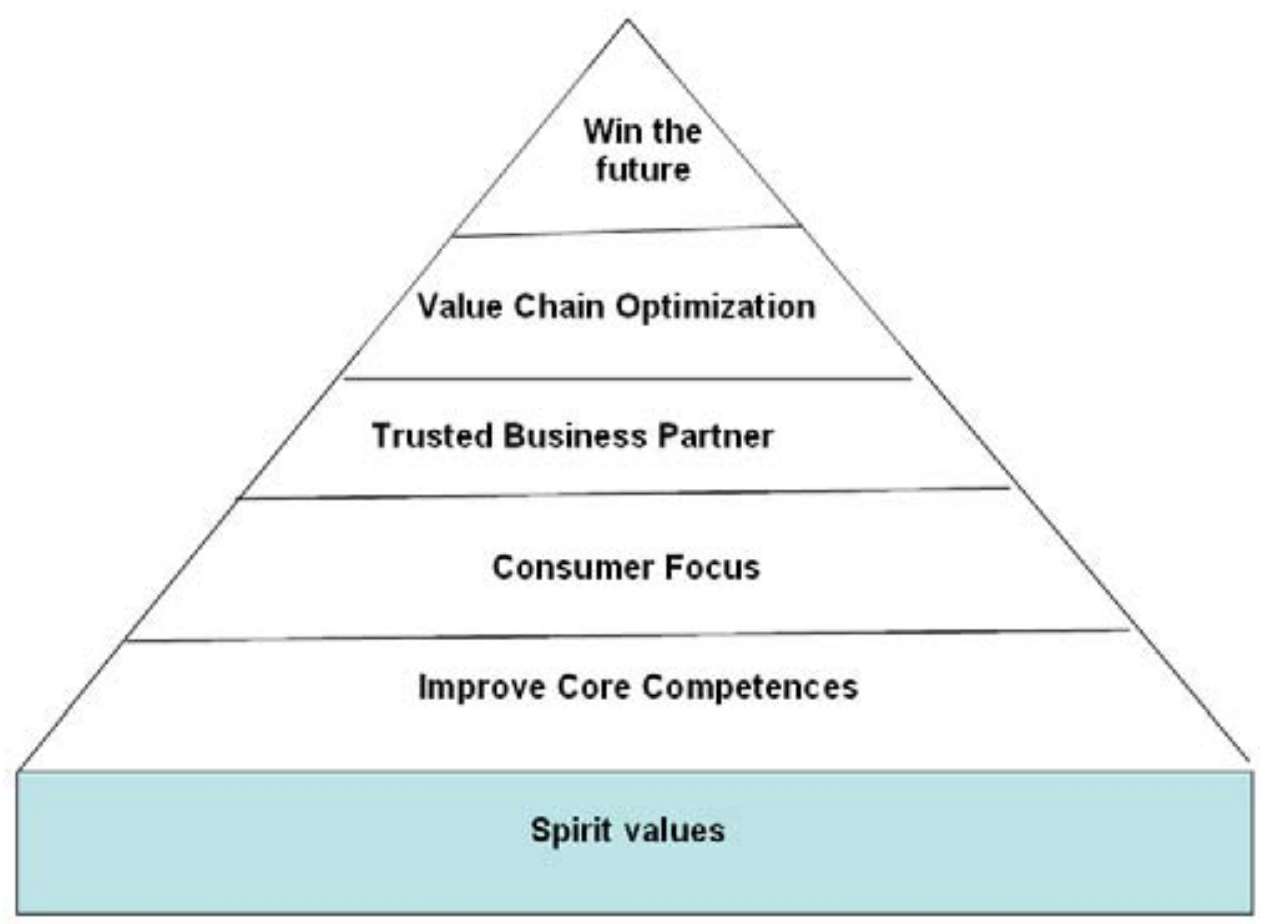

Fig. 3. BSC strategy map

While the financial and customer perspectives describe the desired outcomes from the strategy, the Trusted Business Partner and Value Chain Optimization perspective describes how the partners ought to create these desired outcomes. The Value Chain Optimization perspective identifies the critical few processes that are expected to have the greatest impact on the strategy. A company may for instance want to increase its R\&D investments and reengineer its product development processes, so that it can develop high-performance, innovative products for its value chain partners. This identifies the intangible assets that are most important to the strategy. The objectives in this perspective identify which jobs, which systems, and what kind of climate is required to support the value-creating processes. 
The objectives in the four perspectives are thus linked together by cause-and-effect relationships. From the top it starts with the hypothesis that financial outcomes can only be achieved if targeted customers are satisfied. It then moves on to the customer value proposition that describes how to generate sales and loyalty from targeted customers. Further, the Trusted Business Partner and Value Chain Optimization describe how to create synergy through partner and deliver the customer value proposition. Lastly, the intangible assets that support the Trusted Business Partner processes provide the foundation for the strategy. This cause-and-effect linking of the four perspectives is the structure around which a strategy map is developed. By building a strategy map one forces an alliance to clarify the logic of how it will create value and for whom.

\section{Generalization of the scorecard}

Each of the activities we have defined in Tab. 1 is an opportunity to create synergy and develop core competencies. For Isfahan Textile firms we built its scorecard on a pyramid Fig. 3 to represent how they would become the best downstream marketing business in Iran. Strategic key issues were selected for each of issue demonstrated in Fig .3 and then developed objectives, a Strategy map, measures, and targets for the issues. The process can enable these textile firms to operate as alliance with a coherent and integrated strategy. In this study we focus on the issue one, Improve Core Competences (Tab. 2 shows a summery of that issue.) Improve Core Competences focus impacts all of Isfahan textile business. The objective is to increase rant creation from improving core competences by making alliance. In addition these textile firms need to focus on their core competences and partners to get benefits from rent creation. In Fig. 5 the strategy map and scorecards measures, for this issue are shown.

Table 2. Improve Core Competences focus

\begin{tabular}{l|l}
\hline Key points and rationale & Business case description \\
\hline - Rent creation & - Access new technology \\
- Expansion of resources & $\bullet$ License \\
- Diversification & $\bullet$ Measuring tacit Resources \\
- Imitation & $\bullet$ Learning capability \\
- Resource disposal & \\
\hline
\end{tabular}

In this studies qualitative data dominated by interviews, where the topic and issues to be covered, people to be interviewed and questions to be asked have been determined beforehand but the analysis itself is quantified and inversely. The technique used in this research has been analytic hierarchy process (APH). A typical three-level AHP model involves three basic steps. The first step is to determine the importance of the criteria. It involves an objective or subjective assignment of preference weights to each pair of the defined attributes. The second step involves evaluating each capability alternative against the other attributes of uniqueness. The alternatives are compared among themselves with respect to each attribute; hence a weight vector for each of the alternatives would be assigned. The third step is to synthesize the assignment results. The weight vectors of the criteria and the alternatives need to be combined together to generate a final list of weighting vectors for the capability alternatives. The final list would illustrate which capabilities are more unique than others in the competition (or marketplace).

The decision-makers can conduct the pair wise comparison with the help of user friendly computer software, Expert Choice. The software allows executing each phase of the evaluation and subsequently synthesizing these judgments. We measured the potential of improving core competencies as a result of strategic alliances for 8 textile firms by comparing and scoring measuring factors shown in Fig. 3. To restrict the complexity of the analysis to be performed, the number of evaluation parameters is reduced by grouping together those that are similar and by removing the less meaningful ones. An increase in the number of parameters does not imply a higher degree of analysis accuracy. With a large number of parameters the analysis becomes much more onerous in terms of data required and elaboration time. The results are shown that just four textile firms from eight have the more capacity to have the alliance in order to develop their core competencies. 


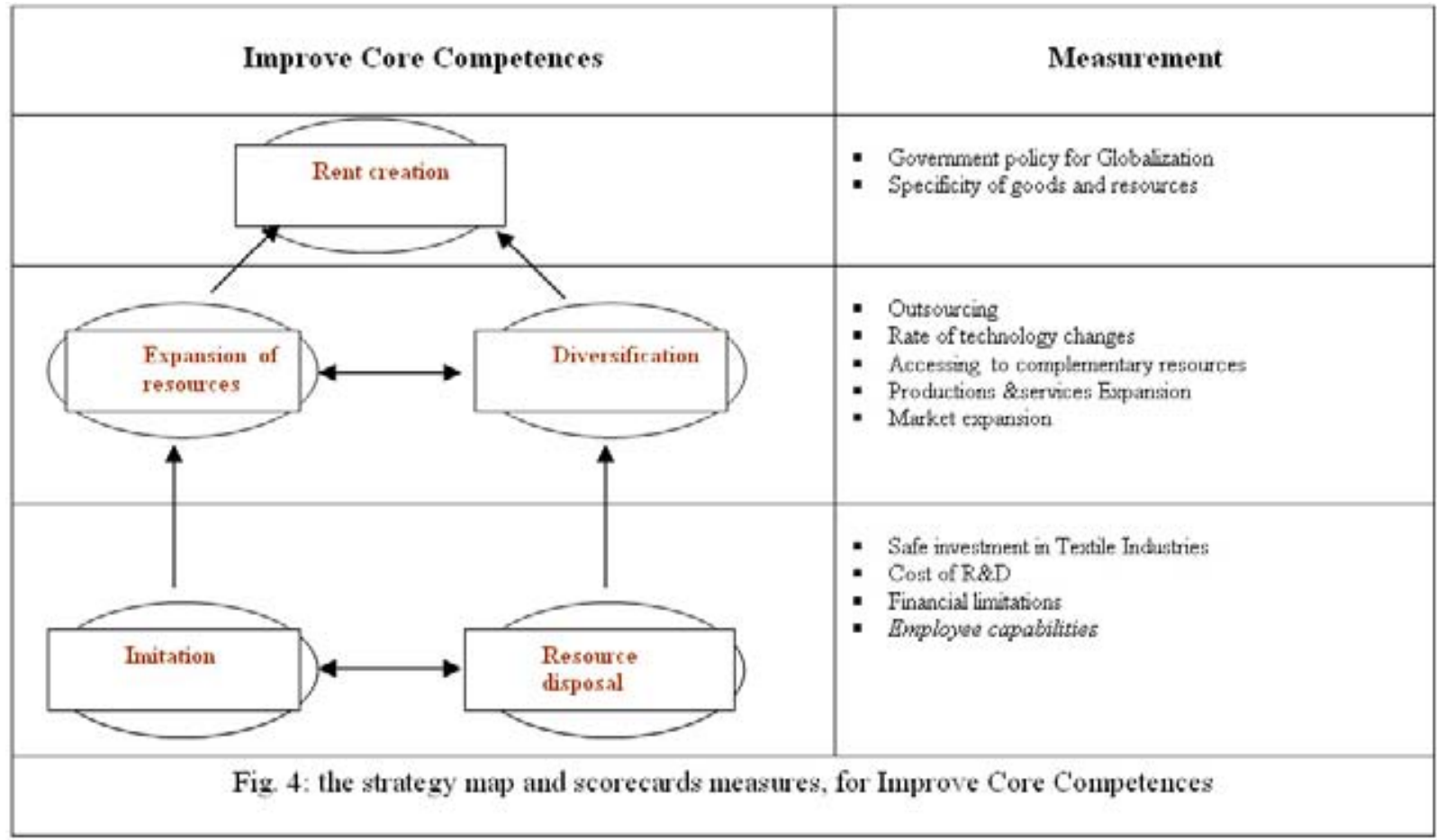

These organizations first should aligned their internal business and then extend their strategic alliance by creating Strategy maps and Balanced Scorecards with their external partners, including suppliers, customers, and competitors. Most firms in this study tend to drive improvement in the operational performance such as cost and quality.

Table 3. Evaluating firms' capabilities to make alliance from improving core competencies perspective

\begin{tabular}{l|cccccccc|c}
\hline ALLIANCE & firm 1 & firm 2 & firm 3 & firm 4 & firm 5 & firm 6 & firm 7 & firm 8 & IDEAL \\
\hline Capabilities & 109.99 & 73.23 & 55.61 & 116.59 & 105.95 & 58.84 & 53.77 & 151.52 & 177.78 \\
\hline Normalized & 61.9 & 41.19136 & 31.3 & 65.6 & 59.6 & 33.1 & 30.2 & 85.2 & 100.0 \\
\hline
\end{tabular}

\section{Conclusion}

Although all alliances in Textile Industries can be undertaken for strategic purposes, it does not mean that they will realize complementary assets, achieve strategic competitiveness, and earn above-average returns. For instance, alliances to reduce competition are more likely to achieve competitive party than competitive advantage. In fact, they are usually undertaken to blunt or slow other competitive strategic or tactical moves, which more than likely results in only average returns. An alliance that is formed by a firm lagging behind its competitors for purpose of improving its core competences and its capabilities is likely to achieve no more than competitive party. Complementary alliances, however, are more likely to create competitive advantage, achieve strategic competitiveness, and earn above-average returns. When potential complementary capabilities between two firms are realized, there is usually a cost saving advantage or creation of new capabilities or both, which enhances performance. Furthermore a firm is able to enter to market quicker through alliance activities than it could otherwise, it may gain at least a short-term competitive advantage. Many supplier and distributor agreement are of this nature.

Uncertainty reduction strategies, on the other hand, are likely to realize only average returns because they attempt to buffer uncertainty and rely, to some degree, on luck. This type of alliance increases the number of options a firm has and thus increases its flexibility and ultimate survival. As such, these alliances are 
important because without them, a firm may experience below-average returns. For example, earlier entrants into the market have established relationships with key firms and, thus, may create stronger barriers to the entry of new competitors. When analyzing the entire work for the final conclusions it can be established, that the composition of the ABSC has been shaped by the assumptions for the prospective motivations of alliances. This in turn, has made the definitions of the objectives more general, which instead should be as customized as possible according to Kaplan and Norton (1996). This dilemma is, however, a consequence very hard to avoid in a case study like this one. The Balanced Scorecard for the prospective Isfahan Textile alliance would look very much like an ordinary BSC as it has the standard four perspectives. Taking a closer look at it would reveal that more focus is on the External Business Process perspective as well as on the strategic perspective, to improve core competences and not on the financial perspective, which is more common.

\section{References}

[1] M. Armstrong. Performance Management Key strategies and practical Guidelines, 2nd edn. London, 2000.

[2] M. Bengtsson, S. Kock. Coo petition in business networks-to cooperate and compete simultaneously. Ind Mark Manage, 2000, 29: 411-426.

[3] L. Divita, N. Cassill. Global partnerships in the textile world. Textile Asia, 2002, 44-48.

[4] J. Dyer, H. Singh. The relational view: Co-operative strategy and sources of interorganisational competitive advantage. Academy of Management Review, 1998, 23(4): 660-679.

[5] L. Fernando. Adding value: Building value-addition alliances, backward linkages in the textile and clothing sector sri lanka creations. 2002.

[6] W. Gilchrist. Modeling failure modes and effects analysis. International Journal of Quality and Reliability Management, 1993, 10(5): 16-20.

[7] D. Halevy, T. Monier, J. Sarrazin. A future for e-alliances. Forbes Magnetic, 2001, 64-106.

[8] J. Harbison, P. Pekar. Smart Alliances: A Practical Guide to Repeatable Success. San Francisco: Josey-Bass Publishers, 1998.

[9] K. Harrigan. Strategic Alliances and Partner Asymmetries. In Cooperative Strategies in International Business, Lexington, 1998.

[10] M. Hitt, R. Hoskisson, R. Ireland. Strategic Management: Competitiveness and Globalization, 3rd edn. Southwestern collage publishing, 1999.

[11] R. Kaplan, D. Norton. Strategy maps: converting intangible assets into tangible outcomes. Harvard Business School Publishing Corporation, Boston, 2004.

[12] R. Kaplan, D. Norton. Alignment: Using the balanced scorecard to create corporate synergies. Harvard Business School Publishing Corporation, 2006.

[13] T. Saaty. How to make a decision: the analytic hierarchy process. European Journal of Operational Research, 1990, 48: 9-26.

[14] W. Wen, W. Wang, T. Wang. A hybrid knowledge-based decision support system for enterprise mergers and acquisitions. Expert Systems with Applications, 2005, 28(3): 569-582. 
Table 1. Score of activity characteristics

\begin{tabular}{|c|c|c|}
\hline Characteristics & Score & Description \\
\hline \multirow[b]{2}{*}{ Evaluation } & 0 & Data do not require any checking or only require simple routine checking \\
\hline & 1 & $\begin{array}{l}\text { Some relevant data must be checked against the Administration's } \\
\text { own records or the documents provided by the citizen, or several financial } \\
\text { and technical data audits conducted by qualified staff }\end{array}$ \\
\hline \multirow{4}{*}{ Inspection } & 0 & No inspection is needed \\
\hline & 1 & Routine inspections are conducted on a small sample \\
\hline & 2 & Inspections are conducted on a broad, randomly selected sample \\
\hline & 3 & Date are inspected on site, in a separate place for the workplace \\
\hline \multirow{4}{*}{$\begin{array}{l}\text { Economic or } \\
\text { social impact }\end{array}$} & 0 & Cost per unit $<12,000 e$, or events with no social repercussion \\
\hline & 1 & Cost per unit between $12,000 e$ and $30,000 e$, or Events with mild repercussion \\
\hline & 2 & Cost per unit between 30,000 and $140,000 e$, or Events affecting a large number of people \\
\hline & 3 & $\begin{array}{l}\text { Cost per unit }>140,000 e \text {, or events affecting the public health system, the environment, or } \\
\text { the Administration's impartiality credibility }\end{array}$ \\
\hline \multirow{4}{*}{ Frequency } & 0 & An event occurring more than 5,000 times a year \\
\hline & 1 & An event occurring between 1,000 and 5,000 times a year \\
\hline & 2 & An event occurring between 100 and 1,000 times a year \\
\hline & 3 & An event occurring less than 100 times a year \\
\hline \multirow{3}{*}{$\begin{array}{l}\text { Number of } \\
\text { documents }\end{array}$} & $\begin{array}{l}0 \\
1\end{array}$ & $\begin{array}{l}\text { Files completed with } 5 \text { or less simple, easily compiled documents } \\
\text { Files including a small volume of documents, but the citizen makes inquiries }\end{array}$ \\
\hline & 2 & $\begin{array}{l}\text { Files with precise rules, aimed at population sectors who need to be explained what } \\
\text { documents must be submitted }\end{array}$ \\
\hline & 3 & $\begin{array}{l}\text { Files involving numerous different documents asking the citizen to do certain things to } \\
\text { fill them in }\end{array}$ \\
\hline \multirow{2}{*}{ People dealing } & 0 & No need to contact citizens, or inquiries are simple \\
\hline & 1 & Files with rules requiring citizens to specify some aspects \\
\hline \multirow[t]{2}{*}{ Software tools } & 0 & $\begin{array}{l}\text { Simple software, or absence of software, or only an operation is automated, or it } \\
\text { facilitates checking but does not avoid it }\end{array}$ \\
\hline & 1 & High automation of tasks, even checks the information requested \\
\hline \multirow{3}{*}{$\begin{array}{l}\text { Procedure } \\
\text { variability }\end{array}$} & 0 & $\begin{array}{l}\text { The procedure is always run in the same way, or } \\
\text { The procedure has slight variations every year }\end{array}$ \\
\hline & 1 & The procedure changes substantially every year \\
\hline & 2 & The procedure is new or periodically repeated \\
\hline
\end{tabular}

between their traits and the operation time logarithm, and values under 5 minutes or over 600 minutes were ruled out.

A stepwise regression analysis and the tests of fit are shown in Tab. 2 and Tab. 3 respectively, under the conditions described.

Table 2. Results of the regression analysis for logarithmic operation time; cases constrained to operation time between 5 and 600 minutes

\begin{tabular}{l|c|c|c|c|c|c}
\hline & Beta & Std.Err. & $\mathrm{B}$ & Std.Err. & $\mathrm{t}(98)$ & $p$-level \\
\hline Intercept & & & 2.6705 & 0.1196 & 22.3267 & 0.0000 \\
\hline Frequency & 0.2873 & 0.0548 & 0.3811 & 0.0727 & 5.2451 & 0.0000 \\
\hline Number of documents & 0.3958 & 0.0492 & 0,6807 & 0.0846 & 8.0464 & 0.0000 \\
\hline Inspection & 0.2471 & 0.0518 & 0.4613 & 0.0967 & 4.7719 & 0.0000 \\
\hline Software tools & -0.1575 & 0.0491 & -1.2953 & 0.4035 & -3.2103 & 0.0018 \\
\hline Evaluation & 0.4081 & 0.0577 & 1.1546 & 0.1633 & 7.0699 & 0.0000 \\
\hline
\end{tabular}

Note: $R=0.88110083, R^{2}=0.77633867$ Adjusted $R^{2}=0.76492738$

$F(5.98)=68.032, p<0.0000$ Std. Error of estimate: 0.67057

The interpretation of the results allows us to understand the clerical work completed within the system scope: (a) the regression model is highly significant, so operation time could be drawn from the activity driver 
Table 3. Regression summary and variance analysis

\begin{tabular}{l|c|c|c|c|c}
\hline & Sums of Squares & Degrees of freedom & Mean Squares & F & $p$-level \\
\hline Regression & 152.9595 & 5 & 30.59189 & 68.03249 & 0.000000 \\
\hline Residual & 44.0673 & 98 & 0.44967 & & \\
\hline Total & 197.0267 & & & & \\
\hline
\end{tabular}

characteristics; (b) reference cycle time is $\exp (2.67)=14.4$ minutes, which is slightly higher than the 12 minute maximum period usually recommended to maximise staff efficiency; (c) when a powerful computer system is used, operation time is $73 \%$ reduced; (d) the effect of the remaining significant characteristics is an increased operation time; for instance, when evaluation is needed, operation time is multiplied by 3.17 ; (e) variability, people dealing, and economic or social impact are not statistically significant; and (f) while the need for inspection, evaluation or the number of documents to be processed clearly affect the amount of work to be done, surprisingly the frequency is also significant; this fact can only be accounted for by the improvement of the work methods, only occurring when tasks reach a high level of repetition.As a consequence, the calculation of predetermined times consists of multiplying base time by the factors in Tab. 4 corresponding to activity driver characteristics.

Table 4. Parameters to calculate predetermined times

\begin{tabular}{l|c|c|c|c}
\hline \multirow{2}{*}{} & \multicolumn{5}{|c}{ Factor per characteristic and score } \\
\cline { 2 - 5 } & 0 & 1 & 2 & 3 \\
\hline Frequency & 1.00 & 1.46 & 2.14 & 3.14 \\
\hline Number of documents & 1.00 & 1.98 & 3.90 & 7.71 \\
\hline Inspection & 1.00 & 1.59 & 2.52 & 3.99 \\
\hline Software tools & 1.00 & 0.27 & & \\
\hline Evaluation & 1.00 & 3.17 & & \\
\hline
\end{tabular}

Anyway, its is important to bear in mind that the model is not intended to accurately estimate every operation time but to provide a conceptual framework and useful tools for comparing efficiency across organizational units doing different jobs. This comparison allows us to identify a reduced number of organizational units with low clerical efficiency, for their subsequent analysis and improvement. For example, the very first result of the application of this methodology to Junta de Comunidades de Castilla la Mancha was the new competence of Direction General of the Public Function to assess the modification proposals of the organizational units staff; with the new developed tools, this assessment could be accomplished in a technical and objective way instead of the more political previous approach leading to a tighter budget control.

\section{Summary}

To date and for the different reasons described throughout the paper, work study has been little used by the Public Administration. However, the Public Administration's growing concerns about efficiency will boost broader implementation. To that end, current circumstances in the Public Administration are to be taken into account; particularly, big evolution efforts must be made in including efficiency as a managerial objective and not as an element related to budget constraints. For that particular purpose, a methodology has been presented to enhance clerical efficiency, allowing a fast and gradual application based on the organization's existing efficiency level. An example for the construction of a calculation model of predetermined times has also been presented together with the most relevant implications of a model of this nature.

\section{References}

[1] G. Gruening. Origin and theoretical basis of the New Public Management. International Public Management Journal, 2001, 4: 1-25. 
[2] T. Lan, A. Chiu, et al. The relationship of continuous improvement and cleaner production on operational performance: An empirical study in electronic manufacturing firms, Taiwan China. International Journal of Management Science and Engineering Management, 2006, 1(1): 71-80.

[3] D. G. Mathiasen. The New Public Management and its critics. International Public Management Journal, 1999, 2(1): 90-111.

[4] OIT. Introduccin al estudio del trabajo. Organizacin Internacional de Trabajo, 1996.

[5] J. R. Thompson, J. Thompson. The management reform agenda, 2001-2010: a report to the Price Waterhouse Coopers endowment for the business of government. International Public Management Journal, 2001, 4: 151-172. 